\title{
Curcumin inhibits the proliferation of airway smooth muscle cells in vitro and in vivo
}

\author{
XIN ZENG, YING CHENG, YUEJUN QU, JIDE XU, ZHIYUAN HAN and TINGTING ZHANG \\ Department of Physiology, Guangzhou Medical University, Guangzhou, Guangdong 510182, P.R. China
}

Received March 21, 2013; Accepted June 20, 2013

DOI: $10.3892 /$ ijmm.2013.1425

\begin{abstract}
The inhibition of the proliferation of airway smooth muscle cells (ASMCs) is crucial for the prevention and treatment of asthma. Recent studies have revealed some important functions of curcumin; however, its effects on the proliferation of ASMCs in asthma remain unknown. Therefore, in this study, we performed in vitro and in vivo experiments to investigate the effects of curcumin on the proliferation of ASMCs in asthma. The thickness of the airway wall, the airway smooth muscle layer, the number of ASMCs and the expression of extracellular signal-regulated kinase (ERK) were significantly reduced in the curcumin-treated group as compared with the model group. Curcumin inhibited the cell proliferation induced by platelet-derived growth factor (PDGF) and decreased the PDGF-induced phosphorylation of ERK1/2 in the rat ASMCs. Moreover, the disruption of caveolae using methyl- $\beta$ cyclodextrin $(\mathrm{M} \beta \mathrm{CD})$ attenuated the anti-proliferative effects of curcumin in the ASMCs, which suggests that caveolin is involved in this process. Curcumin upregulated the mRNA and protein expression of caveolin-1. The data presented in this study demonstrate that the proliferation of ASMCs is inhibited by curcumin in vitro and in vivo; curcumin exerts these effects by upregulating the expression of caveolin-1 and blocking the activation of the ERK pathway.
\end{abstract}

\section{Introduction}

Asthma is a chronic inflammatory disorder of the airways in which many cells and cellular elements play an important role (1). Patients with severe asthma with an incidence rate of $5-10 \%$ account for the high morbidity and health costs; thus, novel treatment strategies for this disorder are urgently required (2).

Correspondence to: Professor Jide Xu, Department of Physiology, Guangzhou Medical University, 195 Dongfengxi Road, Guangzhou, Guangdong 510182, P.R. China

E-mail: xujide@21cn.com

Key words: curcumin, asthma, airway smooth muscle cells, proliferation, caveolin-1, extracellular signal-regulated kinase $1 / 2$, airway remodeling
The airway obstruction in asthma is usually reversible; however, if left untreated, the obstruction may become irreversible due to airway remodeling (3-5). The process of airway remodeling in asthma includes subepithelial basement membrane fibrosis, epithelial goblet cell hyperplasia, an increase in the number of blood vessels and a proliferative state of the airway smooth muscle with increased mass due to hyperplasia and hypertrophy (5). Recent studies have indicated that the increased mass of airway smooth muscle cells (ASMCs) plays a critical role in the histopathological characteristics of airway remodeling (2-4). Thus, this may be a potential therapeutic target for asthma. Several classes of drugs that target the airway smooth muscle, including $\beta$-agonists, anti-cholinergics, antihistamines and anti-leukotrienes were developed decades ago (6). However, these life-long therapies only treat the symptoms, but have little or no effect on the structural alterations in asthma.

Curcumin [diferuloylmethane $\left(\mathrm{C}_{21} \mathrm{H}_{20} \mathrm{O}_{6}\right)$ ], a polyphenol, is derived from the roots (rhizomes) of the plant, Curcuma longa (7). Curcumin has been used as a traditional medicine for the treatment of asthma in China and India since $1900 \mathrm{BC}(8,9)$. Several studies have demonstrated that curcumin has wide range of properties, including anti-inflammatory, antioxidant, anticancer, chemopreventive and chemotherapeutic activities (7,9-12), affecting multiple signaling pathways, such as the extracellular signal-regulated kinase (ERK)1/2 pathway (12-16). The anti-proliferative effects of curcumin have been investigated in various cell lines (17-20). Studies have shown that curcumin inhibits vascular smooth muscle cell (VSMC) proliferation by restoring the expression of caveolin-1, blocking the activation of ERK1/2 (13,15,21-23). However, to our knowledge, whether curcumin inhibits ASMC proliferation in asthma has not been reported to date.

In this study, we investigated whether curcumin inhibits the proliferation of ASMCs in vitro and in vivo. Our results demonstrate that curcumin inhibits the proliferation of ASMCs by upregulating the expression of caveolin-1 and thus blocking the ERK signaling pathway; these results may promote the clinical application of curcumin in asthma.

\section{Materials and methods}

Animals. Eighty female BALB/c mice, weighing approximately 18-22 g, were purchased from the Guangdong Medical Laboratory Animal Center, Foshan, China. The mice were divided into 5 groups ( $n=16$ per group): the control group (normal 
saline-challenged mice treated with normal saline), model group [ovalbumin (OVA)-challenged mice treated with normal saline] and the curcumin-treated groups (OVA-challenged mice treated with 50,100 and $150 \mathrm{mg} / \mathrm{kg}$ curcumin). All mice were kept in well-controlled animal housing facilities, and had free access to tap water and food pellets throughout the experimental period. All experimental procedures involving animals were carried out in accordance with the Guide for the Care and Use of Laboratory Animals and the Institutional Ethical Guidelines for experiments with animals.

Sensitization and challenge with OVA. Mice underwent OVA sensitization and challenge as previously described $(24,25)$ with slight modifications. Mice in the model and curcumintreated groups were immunized by an intraperitoneal (i.p.) injection of $0.2 \mathrm{ml}$ of $50 \mu \mathrm{g} / \mathrm{ml}$ OVA (Sigma-Aldrich Co., St. Louis, MO, USA) on days 0 and 12. The control group received the same volume of physiological saline at the same time. Mice in the model and curcumin-treated groups were then challenged once a day with 5\% OVA (aerosolized for $30 \mathrm{~min}$ ) via the airways between days 18 and 23, while normal saline was administered to the control group in a similar manner. Prolonged inflammation was induced by the subsequent exposure of mice to aerosolized 5\% OVA 3 times a week for $30 \mathrm{~min}$ from day 26 onwards (chronic phase). Mice in the curcumin-treated groups were administered with an i.p. injection of curcumin $30 \mathrm{~min}$ prior to stimulation with OVA, while the others were administered normal saline. The mice were sacrificed on day 55 .

Airway hyper-responsiveness (AHR). The activity of all the mice was observed closely following challenge with OVA. Airway responsiveness was measured indirectly by whole body plethysmography to calculate enhanced pause (Penh: Buxco Technologies, Petersfield, UK). Response to inhaled methacholine (Sigma-Aldrich Co.) at concentrations of 0.78 , $1.56,3.12,6.25,12.5,25$ and $50 \mathrm{mg} / \mathrm{ml}$ were measured for $1 \mathrm{~min}$, as described previously (26). Airway responsiveness activities (Penh\% values) were calculated by the formula $(\mathrm{P}=\mathrm{m} / \mathrm{s} \times 100 \%$, in which $\mathrm{P}, \mathrm{m}$ and $\mathrm{s}$ represent the Penh\% value, methacholine-stimulated Penh value and the salinestimulated Penh value, respectively).

Histology and immunohistochemistry. Paraffin-embedded lung sections from mice of the 5 groups were stained with hematoxylin and eosin (H\&E) to observe the pathological changes in the airways and lung tissue under an optical microscope. We performed immunohistochemistry using the monoclonal mouse antibody to $\alpha$-smooth muscle actin ( $\alpha$-SMA) (1:100, Sigma-Aldrich Co.) and the polyclonal rabbit antibodies to ERK (1:100, Cell Signaling Technology, Inc., Danver, MA, USA). The sections from mice in the 5 groups were deparaffinized, and a $3 \%$ hydrogen peroxide solution was applied for $15 \mathrm{~min}$ to inhibit endogenous peroxidase activity. Antigen retrieval was performed with citrate solution for $45 \mathrm{~min}$. After the sections were blocked with $10 \%$ goat serum in phosphate-buffered saline (PBS) for $20 \mathrm{~min}$, they were incubated with the primary antibody overnight at $4^{\circ} \mathrm{C}$. The horseradish peroxidase (HRP)-conjugated rabbit-anti-mouse immunoglobulin (Sigma-Aldrich Co.) and HRP-conjugated goat-anti-rabbit immunoglobulin (Sigma-Aldrich Co.) were used as the secondary antibodies and 3,3-diaminobenzidine (DAB) (Sigma-Aldrich Co.) was used as the chromogen. Hematoxylin was used for the counterstaining of the sections. For the negative control, the primary antibody was replaced with PBS. The sections were observed under a microscope. The thickness of the airway wall, the thickness of the airway smooth muscle layer, the numbers of smooth muscle cells and the intensity of ERK staining were measured as an average optical density using Image-Pro Plus (IPP) software (Image-Pro Plus 6.0; Media Cybernetics, Inc., Rockville, MD, USA). A non-stained region was selected and set as the background.

Primary cell culture. The ASMCs were cultivated as an explant culture as previously described with slight modifications (27). Briefly, primary rat airway smooth muscle was isolated from the bronchial smooth muscle from 10-12-weekold specific-pathogen-free (SPF) Sprague-Dawley (SD) male rats and the smooth muscle was isolated, cut into sections of 1-2 mm in cubic size, and placed on culture flasks with Dulbecco's modified Eagle's medium/Ham's F-12 (DMEM/ F-12) medium (Gibco, Carlsbad, CA, USA) supplemented with $10 \%$ fetal bovine serum (FBS) in an incubator at $37^{\circ} \mathrm{C}$, $5 \% \mathrm{CO}_{2}$. The ASMCs migrated from the tissue explants and approached confluence around the explants. The culture medium was changed every 3 days. When the cells reached $90-100 \%$ confluence, they were passaged with $0.25 \%$ trypsinEDTA (Gibco). The cells at passage 3 to 6 were used in the following experiments.

Immunofluorescence in vitro. The primary ASMCs were characterized by microscopy and their purity was verified by the immunofluorescence staining of $\alpha$-SMA. The location of caveolin-1 in the ASMCs was also detected by immunofluorescence. After the cells grew to approximately $50 \%$ confluence, they were fixed in the culture plate using $4 \%$ paraformaldehyde for $10 \mathrm{~min}$, permeabilized with $0.3 \%$ Triton X-100, blocked with $5 \%$ bovine serum albumin (BSA) at $37^{\circ} \mathrm{C}$ for $1 \mathrm{~h}$, incubated with monoclonal mouse antibodies against $\alpha$-SMA (1:100, Sigma-Aldrich Co.) and rabbit anti-rat caveolin-1 (1:500, Abcam, Cambridge. UK) respectively overnight at $4^{\circ} \mathrm{C}$, and then labeled with fluorescein isothiocynate (FITC) secondary anti-mouse or anti-rabbit antibody (1:100, Sigma-Aldrich Co.) at $37^{\circ} \mathrm{C}$ for $1 \mathrm{~h}$ in the dark. The nuclei were counterstained with $20 \mu \mathrm{g} / \mathrm{ml}$ propidium iodide (PI) and $1 \mu \mathrm{g} / \mathrm{ml}$ DAPI in methanol for $5 \mathrm{~min}$. The culture plate was washed 3 times between each step for 5 min in $0.1 \mathrm{M}$ PBS (pH 7.4). The cells were examined and images were acquired using a fluorescence microscope.

Cell proliferation assay. The ASMCs were dispensed in a 96-well culture plate at a cell density of $2 \times 10^{4} / \mathrm{ml}$ and incubated at $37^{\circ} \mathrm{C}, 5 \% \mathrm{CO}_{2}$. The cells were divided into 5 groups: i) negative control group (DMEM/F-12 containing $2.5 \% \mathrm{FBS}$ ), ii) positive control group (DMEM/F-12 containing 10\% FBS), iii) proliferation group $[25 \mathrm{ng} / \mathrm{ml}$ platelet-derived growth factor (PDGF) in DMEM/F-12 supplemented with $2.5 \%$ FBS], iv) curcumin-treated group with caveolin-1 (25 $\mu \mathrm{mol} / 1$ curcumin with $25 \mathrm{ng} / \mathrm{ml}$ PDGF in DMEM/F-12 2.5\% FBS), 
and v) curcumin-treated group without caveolin-1 [the cells were pre-treated with $5 \mu \mathrm{mol} / 1$ methyl- $\beta$-cyclodextrin $(\mathrm{M} \beta \mathrm{CD})$ for $60 \mathrm{~min}$, then $25 \mu \mathrm{mol} / 1$ curcumin were added with $25 \mathrm{ng} / \mathrm{ml}$ PDGF in DMEM/F-12 containing 2.5\% FBS]. Cell Counting Kit-8 (CCK-8) assays (Dojindo Laboratories, Kumamoto Japan) were used to measure cell proliferation according to the manufacturer's instructions. After the cells were treated with the culture medium for $6,12,24$ and $48 \mathrm{~h}$, they were incubated in $10 \%$ CCK- 8 diluted in normal culture medium at $37^{\circ} \mathrm{C}$ for $2 \mathrm{~h}$ and the absorbance at $450 \mathrm{~nm}$ (OD at $450 \mathrm{~nm}$ ) was measured. Each group was analyzed in triplicate. The results were expressed as OD values at $450 \mathrm{~nm}$.

Real time PCR. Total RNA was extracted from the ASMCs in each group at 5 time points $(0,4,8,12$ and $24 \mathrm{~h})$ using TRIzol reagent (Invitrogen, Carlsbad, CA, USA) according to the manufacturer's instructions. The concentration, purity and amount of total RNA were determined by ultraviolet spectrometry (ND-1000 spectrophotometer; NanoDrop Technologies, Wilmington, DE, USA). Reverse transcriptase PCR was carried out using the Prime Script ${ }^{\mathrm{TM}}$ RT reagent kit (Takara Bio Inc., Otsu, Japan). The sense and antisense primers for caveolin-1 (GenBank ID: NM_133651) and $\beta$-actin (GenBank ID: NM_031144.2) were synthesized by Takara Bio Inc. The primers used are listed in Table I.

Real-time PCR analyses were performed using SYBR Premix Ex Taq (Takara Bio Inc.). Amplification was performed in an ABI PRISM 7500 Real-Time PCR System with the following temperature profile: a pre-denaturation step of $30 \mathrm{sec}$ at $95^{\circ} \mathrm{C}$, extended at $60^{\circ} \mathrm{C}$ for $34 \mathrm{sec}$, and denaturion for $5 \mathrm{sec}$ at $95^{\circ} \mathrm{C}$ for 40 cycles. The data were calculated using the $2^{-\Delta \Delta \mathrm{Ct}}$ method normalized to $\beta$-actin. Each experiment was performed 3 times.

Western blot analysis. The cells were lysed in cell lysis buffer (Cell Signaling Technology, Inc.). Total protein was extracted by sonication and centrifugation of the cell lysates at $12,000 \times \mathrm{g}$ for $10 \mathrm{~min}$ at $4^{\circ} \mathrm{C}$. Whole-cell extracts were fractionated by $15 \%$ sodium dodecyl sulfate-polyacrylamide gel electrophoresis (SDS-PAGE). Proteins were transferred onto a nitrocellulose membrane (Millipore, Bedford, MA, USA) using a wet transfer apparatus. For immune detection, the membranes were washed and incubated with rabbit anti-rat ERK1/2 polyclonal antibody $(1: 4,000)$, rabbit-anti-rat phospho-ERK1/2 polyclonal antibody (1:4,000), anti-GADPH polyclonal antibody $(1: 2,000$; all from Cell Signaling Technology, Inc., USA), rabbit-anti-rat caveolin-1 polyclonal antibody (1:500, Abcam) and anti- $\beta$-actin monoclonal antibody $\left(1: 2,000\right.$, Sigma-Aldrich Co.) overnight at $4^{\circ} \mathrm{C}$. The signals were amplified using the appropriate HRP-conjugated secondary antibody, and visualized by enhanced chemiluminescence (Pierce Biotechnology, Inc., Rockford, IL, USA).

Statistical analysis. All statistical analyses were performed using SPSS for Windows v.13.0 (SPSS, Chicago, IL, USA). All data are expressed as the means \pm SD. Statistical analyses were carried out using one-way ANOVA, the rank-sum test or least significant difference tests where appropriate. A P-value $<0.05$ was considered to indicate a statistically significant difference.
Table I. Oligonucleotide sequences of primers used for realtime PCR.

\begin{tabular}{ll}
\hline Gene name & \multicolumn{1}{c}{ Sense/antisense primers } \\
\hline Caveolin-1 & 5'-GGGCAACATCTAGAAGCCCAACAA-3' \\
& 5'-CTGATGCACTGAATTCCAATCAGGAA-3' \\
$\beta$-actin & 5'-CTTCCTTCCTGGGTATGGAATC-3' \\
& 5'-GAGATGATCTGGGGGTCTGA-3' \\
\hline
\end{tabular}

\section{Results}

Curcumin decreases the airway responsiveness in the mouse model of airway remodeling. Positive symptoms, such as dysphoria, tachypnea and abdominal spasms were observed in the mice in the model group 5 to 10 min following challenge with OVA, whereas less severe symptoms, including mild dysphoria and tachypnea were observed in the mice treated with curcumin; all the symptoms soon dissipated.

The mice with asthma (model group), the mice with asthma treated with curcumin (curcumin-treated groups) and the untreated normal mice (control group) began to suffer from breathing difficulties after inhaling methacholine at concentrations of $1.56,6.25$ and $25 \mathrm{mg} / \mathrm{ml}$. The airway responsiveness (Penh\%) of the model group and the curcumin-treated groups (treated with various concentrations of curcumin) significantly increased compared with the normal group when methacholine was inhaled at the concentrations of $3.12,6.25,12.5$ and $25 \mathrm{mg} / \mathrm{ml}(\mathrm{P}<0.05)$ and at the concentration of $50 \mathrm{mg} / \mathrm{ml}$ $(\mathrm{P}<0.01)$ (Fig. 1). The airway responsiveness (Penh\%) of the curcumin-treated groups significantly decreased compared with the model group when methacholine was inhaled at the concentrations of $3.12,6.25,12.5,25 \mathrm{mg} / \mathrm{ml}(\mathrm{P}<0.05)$ and at the concentration of $50 \mathrm{mg} / \mathrm{ml}(\mathrm{P}<0.01)$ (Fig. 1).

Effects of curcumin on OVA-induced histopathologicalchanges in lungs. To assess the anti-remodeling effects of curcumin, histopathological experiments were performed. Using H\&E staining, inflammatory cell infiltration in the peribronchial and perivascular areas was observed in OVA-challenged mice. Treatment with curcumin $(50,100$ and $150 \mathrm{mg} / \mathrm{kg})$ markedly reduced the degree of inflammatory cell infiltration in the peribronchial and perivascular areas (Fig. 2, upper panel). OVA induced the proliferation of ASMCs. In the curcumin-treated groups, curcumin inhibited the OVA-induced ASMC proliferation compared with the model group (Fig. 2, middle panel). The expression of $\alpha$-SMA and ERK was detected by immunohistochemistry and the expression of ERK was increased in mice with asthma (Fig. 2, lower panel; ERK protein is stained brown). Curcumin decreased the expression of ERK in the curcumin-treated groups compared with the model group. The bronchial wall thickness (WAi/Pi), the thickness of the smooth muscle layer (WAm/Pi), the number of smooth muscle cells $(\mathrm{N} /$ $\mathrm{Pi}$ ) and the ERK gray values in the ASMCs in each group were measured using IPP software (Table II). In the model group, the thickness of the airway wall, the thickness of the airway smooth muscle layer and the numbers of smooth muscle cells were significantly increased compared with the control group 
Table II. Lung pathology of the mice in the 5 groups.

\begin{tabular}{lcccc}
\hline Group & WAi $/ \mathrm{Pi}(\mu \mathrm{m})$ & WAm/Pi $(\mu \mathrm{m})$ & N/Pi $(/ \mathrm{mm})$ & ERK gray-scale value \\
\hline Control & $5.6 \pm 0.5$ & $1.2 \pm 0.5$ & $12.4 \pm 1.2$ & $68.5 \pm 6.4$ \\
Model & $14.6 \pm 3.6^{\mathrm{b}}$ & $6.4 \pm 1.4^{\mathrm{b}}$ & $35.3 \pm 4.4^{\mathrm{b}}$ & $97.6 \pm 15.2^{\mathrm{b}}$ \\
$50 \mathrm{mg} / \mathrm{kg}$ curcumin & $7.7 \pm 1.7^{\mathrm{a}}$ & $4.2 \pm 1.5^{\mathrm{a}}$ & $25.8 \pm 2.5^{\mathrm{a}}$ & $90.5 \pm 15.8^{\mathrm{a}}$ \\
$100 \mathrm{mg} / \mathrm{kg}$ curcumin & $5.6 \pm 1.5^{\mathrm{a}}$ & $3.2 \pm 1.3^{\mathrm{a}}$ & $16.5 \pm 1.6^{\mathrm{a}}$ & $80.6 \pm 10.3^{\mathrm{a}}$ \\
$150 \mathrm{mg} / \mathrm{kg}$ curcumin & $5.6 \pm 0.7^{\mathrm{a}}$ & $1.5 \pm 0.7^{\mathrm{a}}$ & $12.5 \pm 1.7^{\mathrm{a}}$ & $74.5 \pm 7.1^{\mathrm{a}}$ \\
\hline
\end{tabular}

The data are expressed as the the means $\pm \mathrm{SD}(\mathrm{n}=16)$. ${ }^{\mathrm{a}} \mathrm{P}<0.05$, compared with the model group and ${ }^{\mathrm{b}} \mathrm{P}<0.01$, compared with the control group $\mathrm{Pi}$, internal perimeter; $\mathrm{N}$, number of smooth muscle cells; WAi, inner wall area; WAm, smooth muscle area.

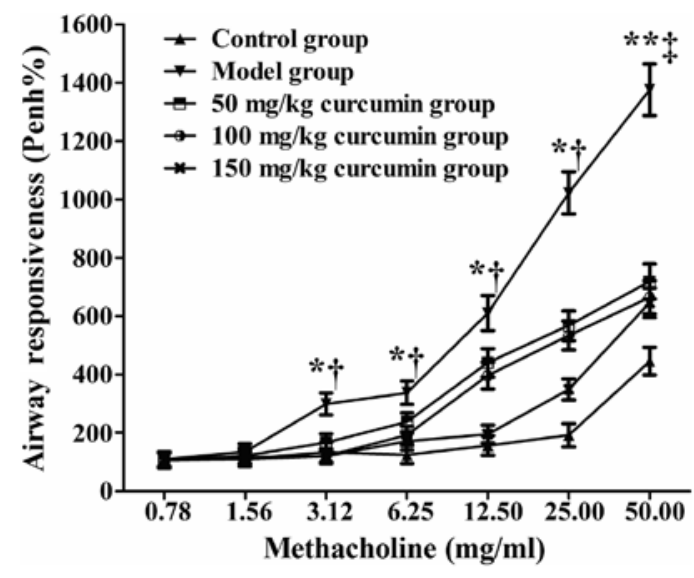

Figure 1. Effect of curcumin on airway hyper-responsiveness (AHR) in mice The AHR of mice was measured by the whole body plethysmography system. The airway responsiveness (Penh\%) of the curcumin-treated groups was significantly decreased compared with the model group. All data are expressed as the means $\pm \mathrm{SD}$ ( $\mathrm{n}=16$ per group), ${ }^{*} \mathrm{P}<0.05$, compared with control group, ${ }^{* * *} \mathrm{P}<0.01$, compared with control group, ${ }^{\dagger} \mathrm{P}<0.05$, compared with curcumintreated groups, ${ }^{\star} \mathrm{P}<0.01$, compared with curcumin-treated groups.

$(\mathrm{P}<0.01)$. In the curcumin-treated groups, the thickness of the airway wall, the thickness of the airway smooth muscle layer and the numbers of smooth muscle cells were significantly decreased compared with the model group $(\mathrm{P}<0.05)$.

Correlation between ERK expression and ASMC proliferation. Semi-quantitative image analysis demonstrated that the expression level of ERK in the airways positively correlated with the thickness of the airway smooth muscle layer $(r=0.745$, $\mathrm{P}<0.05)$, and positively correlated with the number of ASMCs $(\mathrm{r}=0.821, \mathrm{P}<0.05)$.

Rat primary ASMC identification and location of caveolin-1 in ASMCs. The ASMCs generally became adherent within 2 days, and assumed a stretched, spindle-shaped valley-like growth patterns after 4-5 days (Fig. 3A). The ASMCs grew to approximately $90 \%$ confluence after 8-10 days; they were then digested by trypsin and passaged for immunofluorescence staining (Fig. 3B). The cytoplasmic filaments of positive cells were stained green. The percentage of pure ASMCs was approximately $94.32 \%$ using Image Pro Plus 6.0 software.
Caveolin-1 was detected in the ASMC plasma membrane under a fluorescence microscope (Fig. 3C-E).

Effect of curcumin on PDGF-induced ASMC proliferation. Cell proliferation was determined using the CCK- 8 assay as shown in Fig. 4. At 12, 24 and 48 h, the absorbance at $450 \mathrm{~nm}$ was significantly higher in the PDGF + curcumin group compared with the negative control group $(\mathrm{P}<0.05)$. Of note, the ASMC proliferation induced by PDGF in group B peaked at $48 \mathrm{~h}$, compared with the negative control group $(\mathrm{P}<0.01)$. Curcumin $(25 \mu \mathrm{mol} / \mathrm{l})$ significantly decreased the PDGF-induced the proliferation of ASMCs at $24 \mathrm{~h}(\mathrm{P}<0.05)$ (group C compared with group B). After caveolae was disrupted by $M \beta C D$, the PDGF-induced proliferation of ASMCs in group D was markedly increased compared with group $\mathrm{C}$. This suggests that the anti-proliferative effects of curcumin are weakened without caveolin-1; thus, caveolin-1 may play an important role in the anti-proliferative effects of curcumin on ASMCs.

Effect of curcumin on the expression of ERK1/2 protein in ASMCs. After the 4th passage ASMCs were treated with or without curcumin $(25 \mu \mathrm{mol} / \mathrm{l})$ for 30 and $60 \mathrm{~min}$, total protein was extracted for western blot analysis to detect the expression of total ERK1/2 protein and the phosphorylation of ERK1/2 protein. A control group was set up. Treatment with PDGF increased ERK1/2 phosphorylation compared with the control group. The expression of PDGF-induced phosphorylatedERK was significantly decreased following treatment with curcumin (Fig. 5), and phosphorylated ERK could not be detected at $60 \mathrm{~min}$. Curcumin had no effect on the expression of total ERK1/2.

$m R N A$ and protein expression of caveolin-1 following treatment with curcumin. After the rat ASMCs were treated with curcumin $(25 \mu \mathrm{mol} / \mathrm{l})$ for $0,4,8,12$ and $24 \mathrm{~h}$, the mRNA expression of caveolin-1 in the ASMCs was measured by real-time PCR. The result revealed that following treatment with PDGF with or without crucumin for $4 \mathrm{~h}$, the caveolin-1 mRNA expression was increased (compared with the control group) $(\mathrm{P}<0.01)$. The mRNA expression of caveolin-1 was significantly increased in the PDGF + curcumin-treated group compared with the PDGF group $(\mathrm{P}<0.05)$ (Fig. 6A). After the 4th passage ASMCs were treated with PDGF or curcumin and PDGF for $24 \mathrm{~h}$, total protein was extracted for western blot 


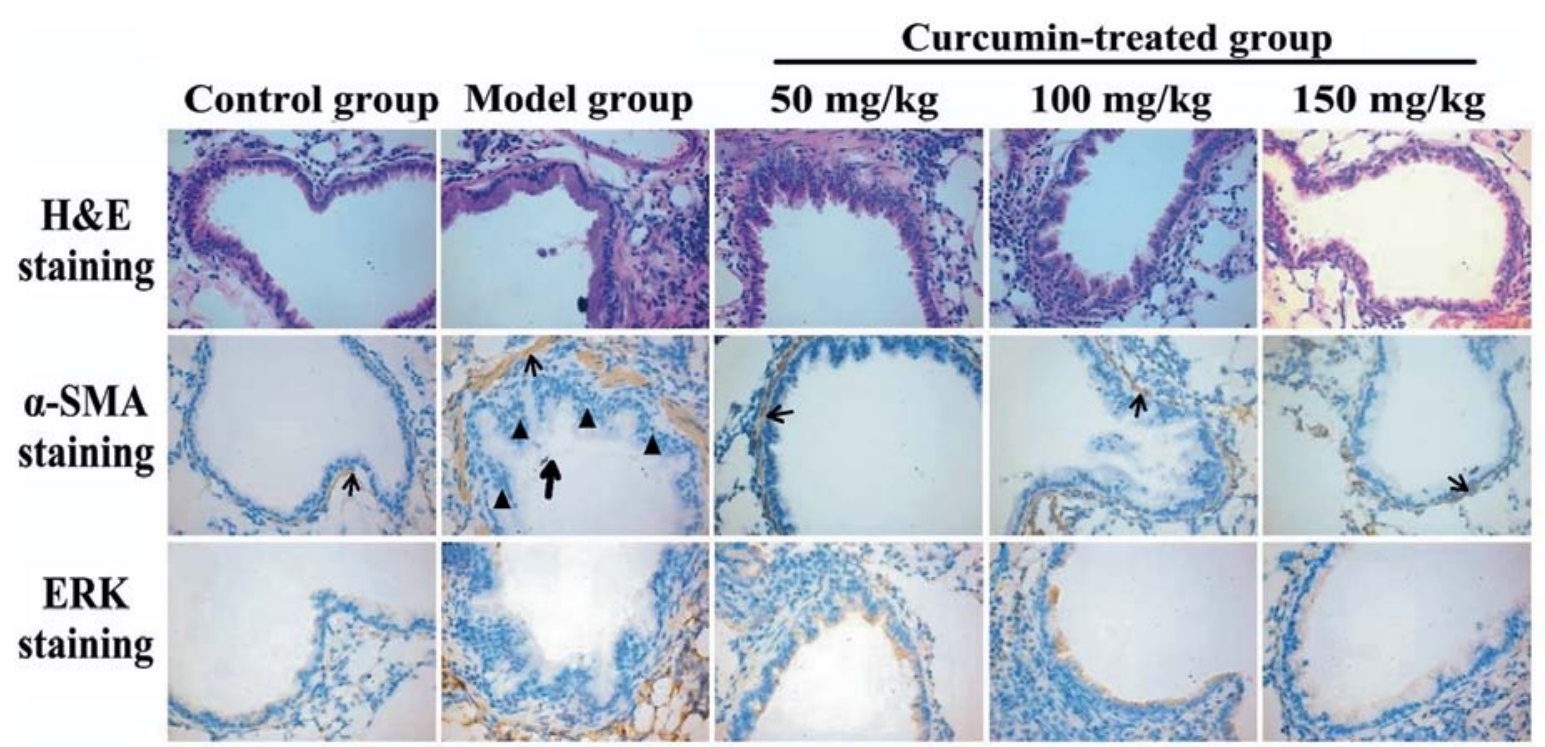

Figure 2. Hematoxylin and eosin (H\&E) staining, $\alpha$-smooth muscle actin ( $\alpha$-SMA) and ERK immunohistochemical staining. (magnification, $x 400)$. The small arrows in $\alpha$-SMA staining figures refer to the airway smooth muscle layer, the black triangles refer to the increased mucosal folds and the large arrow refers to the fallen-off bronchial mucosa. In the control group: alveolar walls had structural integrity, the thickness of the alveolar walls was normal, alveolar epithelial cells were arranged in order, smooth muscle layer was discontinuous and the expression of ERK was not observed. In the model group: eosinophilic infiltration was detected around the bronchi and blood vessels; the number of bronchi mucosal folds was increased and some of the bronchial mucosa fell off; a thicker alveolar wall and continuous smooth muscle layer were observed; the expression of ERK was markedly increased. In the curcumin-treated groups: compared with the model group, treatment with curcumin decreased the pathological changes, the thickness of smooth muscle layer and the expression of ERK in the lung sections of the ovalbumin (OVA)-challenged mice with asthma.

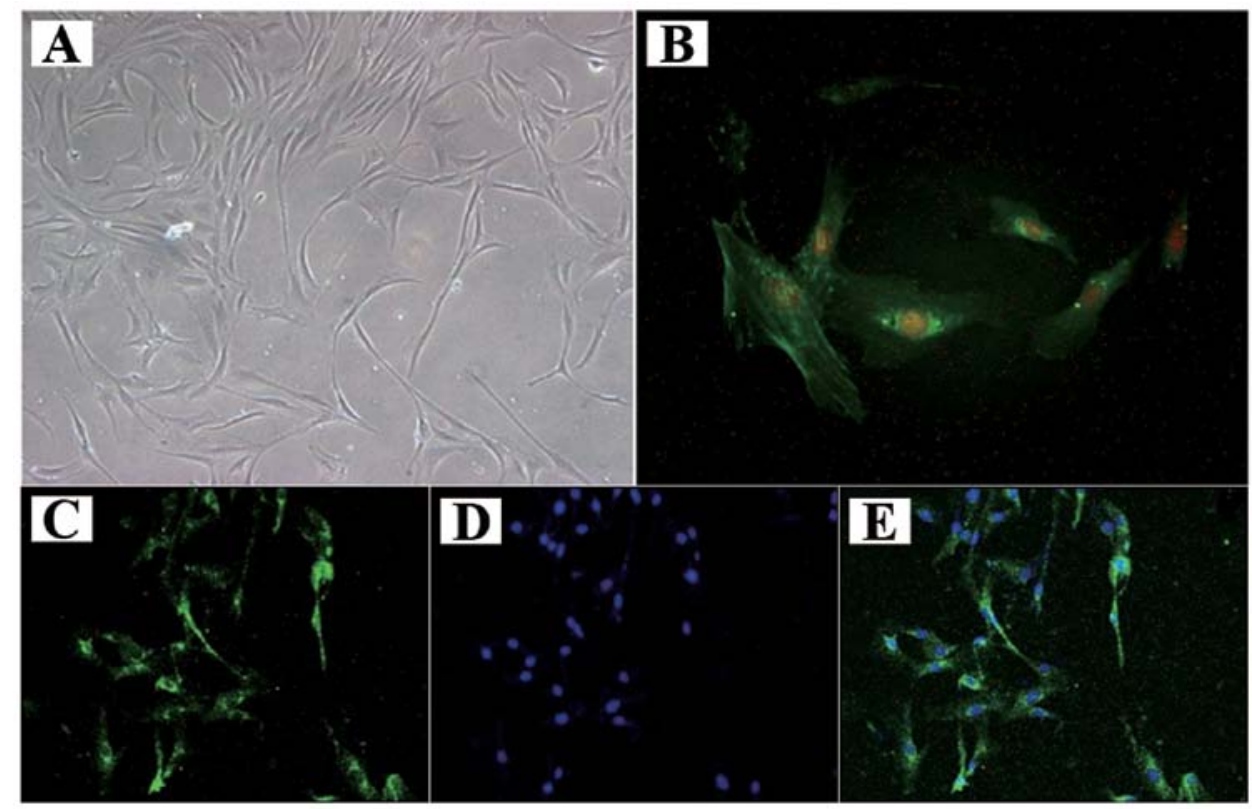

Figure 3. Identification of primary airway smooth muscle cells (ASMCs) and the location of caveolin-1 on the ASMC membrane. (A) ASMCs assumed a 'peak and valley' growth pattern, as observed under a light microscope (magnification, x100). (B) Mouse anti-rat $\alpha$-SMA antibody and FITC-labeled secondary antimouse IgG were used for the identification of rat ASMCs, and the cells were observed under a fluorescence microscope; the cytoplasm showed green positive staining. The nuclei were stained with propidium iodide (PI) and showed orange positive staining under a fluorescence microscopy. (magnification, $\mathrm{x} 400$ ). (C) Rabbit anti-rat caveolin-1 antibody and FITC-labeled secondary goat anti-rabbit IgG was used for detecting the location of caveolin-1 in the rat ASMCs; caveolin-1 showed green positive staining under a fluorescence microscope (magnification, x200). (D) The nuclei were stained with DAPI and showed blue positive staining under a fluorescence microscope (magnification, x200); (C and D) were merged into (E) (magnification, x200).

analysis to detect the expression of caveolin-1 protein. The results are shown in Fig. 6B. Compared with the PDGF group, the protein expression of caveolin-1 in the cucumin + PDGF group was significantly increased $(\mathrm{P}<0.01)$.

\section{Discussion}

Asthma is traditionally defined as a chronic disease characterized by airway inflammation, AHR and airway remodeling. In 


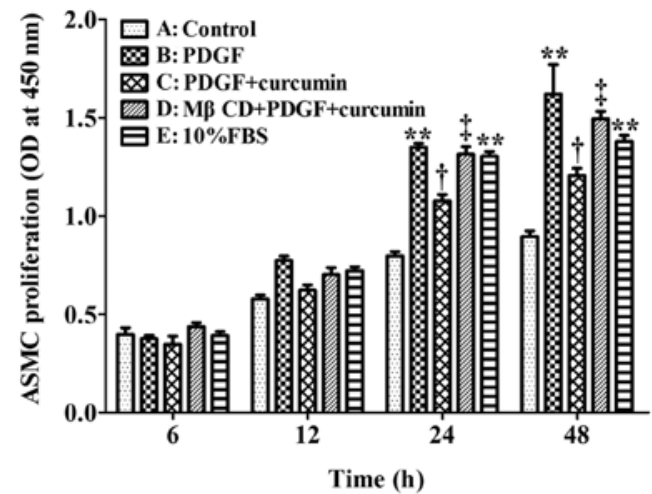

Figure 4. Curcumin inhibits the platelet-derived growth factor (PDGF)-induced proliferation of airway smooth muscle cells (ASMCs). The cell viability of the ASMCs treated with curcumin was examined using CCK-8 at 6, 12, 24 and $48 \mathrm{~h}$. The data are expressed as the means $\pm \mathrm{SD}, \mathrm{n}=3$. ${ }^{* *} \mathrm{P}<0.01$, compared with the control group; ${ }^{\dagger} \mathrm{P}<0.05$, compared with group $\mathrm{B}$; and ${ }^{\dagger} \mathrm{P}<0.05$, compared with group $\mathrm{C}$.

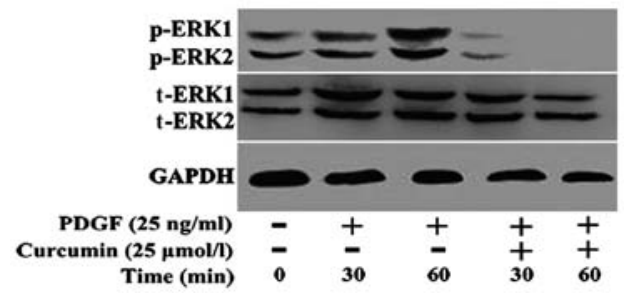

Figure 5. Curcumin inhibits the platelet-derived growth factor (PDGF)induced phosphorylation of extracellular signal-regulated kinase $1 / 2$ (ERK1/2) protein in airway smooth muscle cells (ASMCs). The 4th passage ASMCs were treated with or without curcumin for 30 and $60 \mathrm{~min}$. Western blot analyses were performed using whole-cell fractions of cell lysates. Results are representative of 3 separate experiments. p-ERK1, phosphorylated-ERK1 p-ERK2, phosphorylated-ERK2; t-ERK1, total ERK1; t-ERK2, total ERK2.

a previous study, Chung examined patients with asthma using airway histopathology and lung function dynamic observation and indicated that a series of structural changes could be found in the airway wall in the patients with asthma (5). Among the histopathological characteristics of airway remodeling, previous studies have indicated that the increased mass of ASMCs plays a critical role $(2,4,5,28,29)$. Due to their important role in airway remodeling, ASMCs may be a potential therapeutic target for the treatment of patients with asthma.

Curcumin has been used in indigenous medicine for the treatment of a variety of inflammatory conditions and chronic diseases $(9,13,14,23)$ and studies have mainly focused on the effects of curcumin on inhibiting bronchial inflammation (30-34). However, limited studies have investigated the effects of curcumin on structural changes in asthma, such as ASMC proliferation in airway remodeling. Therefore, in this study, we performed in vitro and in vivo experiments to examine the effects of curcumin on the proliferation of ASMCs and to elucidate the underlying mechanisms. Our findings demonstrate that curcumin inhibits the proliferation of ASMCs both in vitro and in vivo.

In in vivo experiments, we used OVA-challenged mice to establish a model of chronic asthma airway remodeling; the curcumin-treated groups were administered various doses of
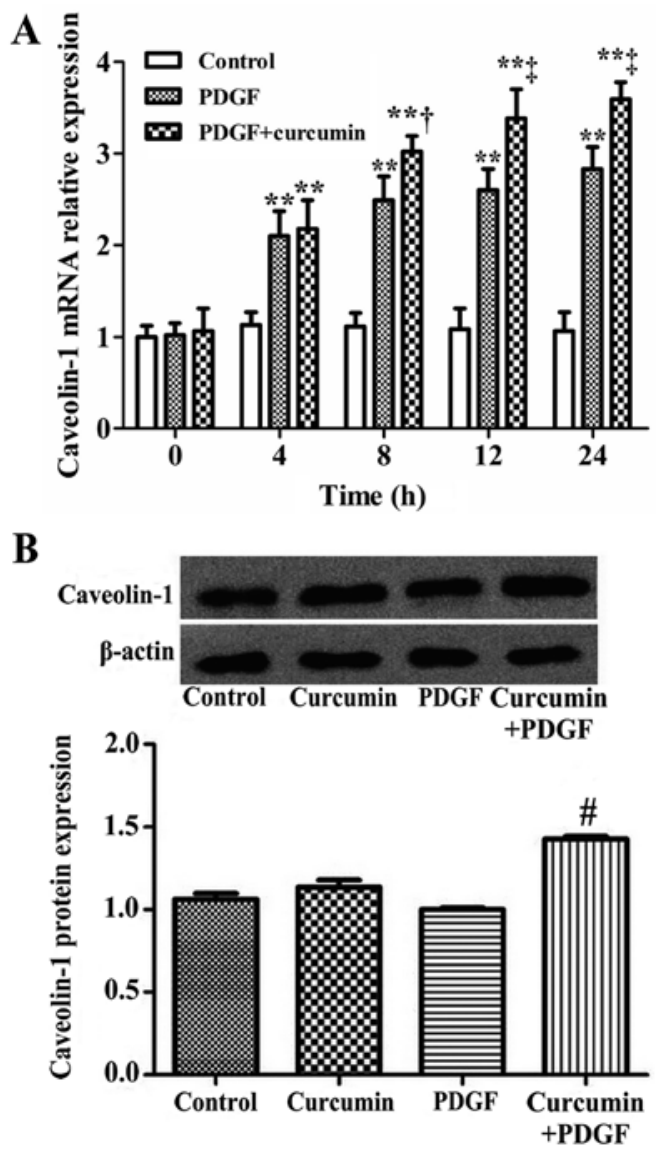

Figure 6. Curcumin increases the mRNA and protein expression of caveolin-1 in airway smooth muscle cells (ASMCs). (A) After the ASMCs were treated with curcumin for $0,4,8,12$ and $24 \mathrm{~h}$, the mRNA expression of caveolin-1 in the ASMCs was measured by real-time PCR. The data are expressed as the mean $\pm \mathrm{SD}, \mathrm{n}=3$. $^{* *} \mathrm{P}<0.01$, compared with the control group; ${ }^{\dagger} \mathrm{P}<0.05$, compared with the platelet-derived growth factor (PDGF) group and ${ }^{\mathrm{P}} \mathrm{P}<0.01$, compared with the PDGF group. (B) Total proteins from the 4th passage ASMCs were used for western blot analysis to detect the protein expression of caveolin-1. The data are expressed as the means $\pm \mathrm{SD}, \mathrm{n}=3,{ }^{\#} \mathrm{P}<0.01$, compared with the PDGF group.

curcumin by an i.p. injection prior to challenge with OVA. The mouse model of airway remodeling induced by OVA has previously been used in a number of studiesl; however, the majority of these studies focused on the inflammatory infiltration in this model. Our results were identical with those from previous studies (30-33). Our findings indicated that the symptoms of an asthma attack dissipated following treatment with curcumin and that curcumin significantly reduced the airway responsiveness. In addition, we paid particular attention to the changes in airway smooth muscle. We found that following treatment with curcumin, the thickness of the airway wall and the bronchial smooth muscle layer became thinner and the number of smooth muscle cells decreased; the most significant changes were observed in the high-dose curcumin-treated group. These results demonstrate that the administration of curcumin inhibits the proliferation of ASMCs in vivo.

In in vitro experiments, we stimulated the proliferation of primary rat ASMCs by PDGF and provided a proliferative experimental model for the study of asthma at the cellular and molecular level. Our results revealed that curcumin inhibited the PDGF-induced proliferation of ASMCs in vitro. 
The mitogen-activated protein kinase (MAPK) signaling cascade has been shown to play an important role in the activation of various cells (35-38). It is activated by the 3-tiered sequential phosphorylation of MAPK kinase, MAPK/ERK kinase (MEK) and MAPK. There are 3 major groups of MAPK in mammalian cells, including ERK, p38 MAPK and c-Jun $\mathrm{N}$-terminal kinase. Accumulating evidence has shown that ERK plays a crucial role in human ASMC growth. A previous study demonstrated that ERK activity in the lungs of asthmatic mice was significantly higher compared with normal mice (39). ERK activation is necessary for the proliferation of ASMCs (4). In addition, PDGF and other growth factors are promoters of ERK1/2 (p42/44 MAPK) expression and the activation of phosphorylation, which are closely associated with the proliferation of smooth muscle cells (27,40-44). Thus, the ERK signaling pathway plays a crucial role in the pathological process of airway remodeling in asthma. The results of our study are in accordance with these findings; we found that the phosphorylated-ERK1/2 protein levels were significantly decreased following the treatment of ASMCs with curcumin. This suggests that the inhibition of the activation of ERK $1 / 2$ by curcumin is involved in the inhibition of ASMC proliferation. We provide evidence that curcumin inhibits ASMC proliferation and that caveolin-1 plays a crucial role in this process; the involvement of caveolin-1 is partly due to the fact that it has the ability to regulate the ERK 1/2 pathway.

We found that curcumin significantly inhibited the PDGF-induced proliferation of ASMCs and that this effect was significantly attenuated by $\mathrm{M} \beta \mathrm{CD}$. The expression of caveolin-1 was significantly increased in the curcumin-treated group as compared with the PDGF group in our study. Caveolae are small vesicular invaginations of the cell membrane. It is within this organelle that cells perform transcytosis and signal transduction. Caveolae are composed of a mixture of lipids and proteins (45-50). The chief structural proteins of caveolae are caveolins (caveolin-1, caveolin-2 and caveolin-3), and caveolin-1 appears to be an essential component of caveolae (51-57). Evidence suggests that caveolin-1 regulates the ERK1/2 pathway during cell proliferation $(55,58-60)$. Buitrago and Boland found that when proliferating mouse skeletal myoblastic cells were pre-treated with $\mathrm{M} \beta C D$, a caveolae-disrupting agent, the $1 \alpha, 25(\mathrm{OH})_{2} \mathrm{D}_{3}$-dependent activation of ERK1/2, p38 MAPK and c-Src was suppressed (58). Furthermore, studies on human ASMCs have shown that caveolae and caveolin-1 coordinate PDGF receptor signaling, leading to myocyte proliferation, and inhibit the constitutive activity of p42/p44 MAPK, sustaining cell quiescence (55). These data are in accordance with those in the study by Peterson $e t a l$, who showed that the treatment of VSMCs with PDGF for $24 \mathrm{~h}$ resulted in a loss of caveolin-1 protein expression and plasma membrane-associated caveolae (21). The data mentioned above indicate that caveolin-1 is an important negative regulator of cell proliferation and PDGF signaling events. Our results therefore suggest that caveolin-1 plays a crucial role in the anti-proliferative effects of curcumin through the ERK1/2 pathway.

In conclusion, we demonstrate that curcumin inhibits the proliferation of ASMCs in vitro and in vivo; the possible mechanisms behind the inhibitory effects of curcumin may be the upregulation of the expression of caveolin-1 and the blocking of the ERK pathway, thereby inhibiting the proliferation of
ASMCs. Our findings provide new insight into the application of curcumin in the prevention and treatment of asthma, particularly airway remodeling in severe asthma.

\section{Acknowledgements}

This study was supported by grants from the Guangzhou Science and Technology Committee (no. 2008J1-C261) and the Guangzhou University Science and Technology Project (no. 10A149), China.

\section{References}

1. Bateman ED: Global strategy for asthma management and prevention 2009 (update). Report of Global Initiative for Asthma 2009: 2, 2009.

2. Girodet PO, Ozier A, Bara I, Tunon de Lara JM, Marthan R and Berger P: Airway remodeling in asthma: new mechanisms and potential for pharmacological intervention. Pharmacol Ther 130: 325-337, 2011.

3. Delacourt C: Bronchial changes in untreated asthma. Arch Pediatr 11 (Suppl 2): 71s-73s, 2004 (In French).

4. Black JL, Roth M, Lee J, Carlin S and Johnson PR: Mechanisms of airway remodeling. Airway smooth muscle. Am J Respir Crit Care Med 164: S63-S66, 2001.

5. Chung KF: The role of airway smooth muscle in the pathogenesis of airway wall remodeling in chronic obstructive pulmonary disease. Proc Am Thorac Soc 2: 347-354, 2005.

6. Siddiqui S, Redhu NS, Ojo OO, et al: Emerging airway smooth muscle targets to treat asthma. Pulm Pharmacol Ther 26: 132-144, 2012.

7. Bar-Sela G, Epelbaum R and Schaffer M: Curcumin as an anti-cancer agent: review of the gap between basic and clinical applications. Curr Med Chem 17: 190-197, 2010.

8. Anand P, Sundaram C, Jhurani S, Kunnumakkara AB and Aggarwal BB: Curcumin and cancer: an 'old-age' disease with an 'age-old' solution. Cancer Lett 267: 133-164, 2008.

9. Schaffer M, Schaffer PM, Zidan J and Bar Sela G: Curcuma as a functional food in the control of cancer and inflammation. Curr Opin Clin Nutr Metab Care 14: 588-597, 2011.

10. Ammon HP and Wahl MA: Pharmacology of Curcuma longa. Planta Med 57: 1-7, 1991.

11. Hatcher H, Planalp R, Cho J, Torti FM and Torti SV: Curcumin: from ancient medicine to current clinical trials. Cell Mol Life Sci 65: 1631-1652, 2008.

12. Aggarwal BB and Harikumar KB: Potential therapeutic effects of curcumin, the anti-inflammatory agent, against neurodegenerative, cardiovascular, pulmonary, metabolic, autoimmune and neoplastic diseases. Int J Biochem Cell Biol 41: 40-59, 2009.

13. Yang X, Thomas DP, Zhang X, et al: Curcumin inhibits plateletderived growth factor-stimulated vascular smooth muscle cell function and injury-induced neointima formation. Arterioscler Thromb Vasc Biol 26: 85-90, 2006.

14. Wong TF, Takeda T, Li B, et al: Curcumin disrupts uterine leiomyosarcoma cells through AKT-mTOR pathway inhibition. Gynecol Oncol 122: 141-148, 2011.

15. Laporte JC, Moore PE, Baraldo S, et al: Direct effects of interleukin-13 on signaling pathways for physiological responses in cultured human airway smooth muscle cells. Am J Respir Crit Care Med 164: 141-148, 2001.

16. Weng SH, Tsai MS, Chiu YF, Kuo YH, Chen HJ and Lin YW: Enhancement of mitomycin C-induced cytotoxicity by curcumin results from down-regulation of MKK1/2-ERK1/2-mediated thymidine phosphorylase expression. Basic Clin Pharmacol Toxicol 110: 298-306, 2012.

17. Saab MB, Bec N, Martin M, et al: Differential effect of curcumin on the nanomechanics of normal and cancerous mammalian epithelial cells. Cell Biochem Biophys 65: 399-411, 2012.

18. Dhandapani KM, Mahesh VB and Brann DW: Curcumin suppresses growth and chemoresistance of human glioblastoma cells via AP-1 and NFkappaB transcription factors. J Neurochem 102: 522-538, 2007.

19. Yang CL, Liu YY, Ma YG, et al: Curcumin blocks small cell lung cancer cells migration, invasion, angiogenesis, cell cycle and neoplasia through Janus kinase-STAT3 signalling pathway. PLoS One 7: e37960, 2012. 
20. Chen JW, Tang YL, Liu H, et al: Anti-proliferative and antimetastatic effects of curcumin on oral cancer cells. Hua Xi Kou Qiang Yi Xue Za Zhi 29: 83-86, 2011 (In Chinese).

21. Peterson TE, Guicciardi ME, Gulati R, et al: Caveolin-1 can regulate vascular smooth muscle cell fate by switching plateletderived growth factor signaling from a proliferative to an apoptotic pathway. Arterioscler Thromb Vasc Biol 23: 1521-1527, 2003.

22. Luo DX, Cheng J, Xiong Y, et al: Static pressure drives proliferation of vascular smooth muscle cells via caveolin-1/ERK1/2 pathway. Biochem Biophys Res Commun 391: 1693-1697, 2010.

23. Qin L, Yang YB, Tuo QH, et al: Effects and underlying mechanisms of curcumin on the proliferation of vascular smooth muscle cells induced by Chol:MbetaCD. Biochem Biophys Res Commun 379: 277-282, 2009.

24. McMillan SJ and Lloyd CM: Prolonged allergen challenge in mice leads to persistent airway remodelling. Clin Exp Allergy 34: 497-507, 2004.

25. Lloyd CM, Gonzalo JA, Nguyen T, et al: Resolution of bronchial hyperresponsiveness and pulmonary inflammation is associated with IL-3 and tissue leukocyte apoptosis. J Immunol 166: 2033-2040, 2001.

26. Hamelmann E, Schwarze J, Takeda K, et al: Noninvasive measurement of airway responsiveness in allergic mice using barometric plethysmography. Am J Respir Crit Care Med 156: 766-775, 1997.

27. Chen $\mathrm{G}$ and Khalil N: TGF-betal increases proliferation of airway smooth muscle cells by phosphorylation of map kinases. Respir Res 7: 2, 2006

28. Tang ML, Wilson JW, Stewart AG and Royce SG: Airway remodelling in asthma: current understanding and implications for future therapies. Pharmacol Ther 112: 474-488, 2006.

29. Nath P, Leung SY, Williams A, et al: Importance of $\mathrm{p} 38$ mitogenactivated protein kinase pathway in allergic airway remodelling and bronchial hyperresponsiveness. Eur J Pharmacol 544: 160-167, 2006.

30. Oh SW, Cha JY, Jung JE, et al: Curcumin attenuates allergic airway inflammation and hyper-responsiveness in mice through NF- $\mathrm{BB}$ inhibition. J Ethnopharmacol 136: 414-421, 2011.

31. Moon DO, Kim MO, Lee HJ, et al: Curcumin attenuates ovalbumin-induced airway inflammation by regulating nitric oxide. Biochem Biophys Res Commun 375: 275-279, 2008.

32. Karaman M, Firinci F, Cilaker S, et al: Anti-inflammatory effects of curcumin in a murine model of chronic asthma. Allergol Immunopathol (Madr) 40: 210-214, 2012.

33. Venkatesan N, Punithavathi D and Babu M: Protection from acute and chronic lung diseases by curcumin. Adv Exp Med Biol 595: 379-405, 2007.

34. Sharafkhaneh A, Velamuri S, Badmaev V, Lan C and Hanania N The potential role of natural agents in treatment of airway inflammation. Ther Adv Respir Dis 1: 105-120, 2007.

35. Nel AE: T-cell activation through the antigen receptor. Part 1: signaling components, signaling pathways, and signal integration at the T-cell antigen receptor synapse. J Allergy Clin Immunol 109: 758-770, 2002.

36. Jacob A, Cooney D, Pradhan M and Coggeshall KM: Convergence of signaling pathways on the activation of ERK in B cells. J Biol Chem 277: 23420-23426, 2002.

37. Gauld SB, Dal Porto JM and Cambier JC: B cell antigen receptor signaling: roles in cell development and disease. Science 296: 1641-1642, 2002.

38. Nadler MJ, Matthews SA, Turner H and Kinet JP: Signal transduction by the high-affinity immunoglobulin $\mathrm{E}$ receptor $\mathrm{Fc}$ epsilon RI: coupling form to function. Adv Immunol 76: 325-355, 2000.

39. Duan W, Chan JH, Wong CH, Leung BP and Wong WS: Antiinflammatory effects of mitogen-activated protein kinase kinase inhibitor U0126 in an asthma mouse model. J Immunol 172 7053-7059, 2004

40. De S, Zelazny ET, Souhrada JF and Souhrada M: Role of phospholipase $\mathrm{C}$ and tyrosine kinase systems in growth response of human airway smooth muscle cells. Am J Physiol 270 L795-L802, 1996
41. Walker TR, Moore SM, Lawson MF, Panettieri RA Jr and Chilvers ER: Platelet-derived growth factor-BB and thrombin activate phosphoinositide 3-kinase and protein kinase B: role in mediating airway smooth muscle proliferation. Mol Pharmacol 54: 1007-1015, 1998.

42. Kumar A, Lnu S, Malya R, et al: Mechanical stretch activates nuclear factor-kappaB, activator protein-1, and mitogen-activated protein kinases in lung parenchyma: implications in asthma. FASEB J 17: 1800-1811, 2003.

43. Chiou YL, Shieh JJ and Lin CY: Blocking of Akt/NF-kappaB signaling by pentoxifylline inhibits platelet-derived growth factor-stimulated proliferation in Brown Norway rat airway smooth muscle cells. Pediatr Res 60: 657-662, 2006.

44. Bai J, Liu XS, Xu YJ, Zhang ZX, Xie M and Ni W: The effect of ERK signaling pathway on cell apoptosis in airway smooth muscle cells of chronic asthmatic rats. Xi Bao Yu Fen Zi Mian Yi Xue Za Zhi 26: 738-741, 2010 (In Chinese).

45. Schlegel A, Volonte D, Engelman JA, et al: Crowded little caves: structure and function of caveolae. Cell Signal 10: 457-463, 1998.

46. Shaul PW and Anderson RG: Role of plasmalemmal caveolae in signal transduction. Am J Physiol 275: L843-L851, 1998.

47. Anderson RG: The caveolae membrane system. Annu Rev Biochem 67: 199-225, 1998

48. Okamoto T, Schlegel A, Scherer PE and Lisanti MP: Caveolins, a family of scaffolding proteins for organizing 'preassembled signaling complexes' at the plasma membrane. J Biol Chem 273: 5419-5422, 1998

49. Couet J, Belanger MM, Roussel E and Drolet MC: Cell biology of caveolae and caveolin. Adv Drug Deliv Rev 49: 223-235, 2001.

50. Razani B, Woodman SE and Lisanti MP: Caveolae: from cell biology to animal physiology. Pharmacol Rev 54: 431-467, 2002.

51. Schubert W, Frank PG, Woodman SE, et al: Microvascular hyperpermeability in caveolin-1 (-/-) knock-out mice. Treatment with a specific nitric-oxide synthase inhibitor, L-NAME, restores normal microvascular permeability in Cav-1 null mice. J Biol Chem 277: 40091-40098, 2002.

52. Ramirez MI, Pollack L, Millien G, Cao YX, Hinds A and Williams MC: The alpha-isoform of caveolin-1 is a marker of vasculogenesis in early lung development. J Histochem Cytochem 50: 33-42, 2002

53. Thyberg J: Caveolin-1 and caveolae act as regulators of mitogenic signaling in vascular smooth muscle cells. Arterioscler Thromb Vasc Biol 23: 1481-1483, 2003.

54. Miyawaki-Shimizu K, Predescu D, Shimizu J, Broman M, Predescu S and Malik AB: siRNA-induced caveolin-1 knockdown in mice increases lung vascular permeability via the junctional pathway. Am J Physiol Lung Cell Mol Physiol 290: L405-L413, 2006.

55. Gosens R, Stelmack GL, Dueck G, et al: Role of caveolin-1 in p42/p44 MAP kinase activation and proliferation of human airway smooth muscle. Am J Physiol Lung Cell Mol Physiol 291: L523-L534, 2006.

56. Sun Y, Hu G, Zhang X and Minshall RD: Phosphorylation of caveolin-1 regulates oxidant-induced pulmonary vascular permeability via paracellular and transcellular pathways. Circ Res 105: 676-685, 615 p following 685, 2009.

57. Feng H, Guo L, Song Z, et al: Caveolin-1 protects against sepsis by modulating inflammatory response, alleviating bacterial burden, and suppressing thymocyte apoptosis. J Biol Chem 285: 25154-25160, 2010.

58. Buitrago $\mathrm{C}$ and Boland R: Caveolae and caveolin-1 are implicated in $1 \alpha, 25(\mathrm{OH})_{2}$-vitamin D3-dependent modulation of Src, MAPK cascades and VDR localization in skeletal muscle cells. J Steroid Biochem Mol Biol 121: 169-175, 2010.

59. Park JH, Ryu JM and Han HJ: Involvement of caveolin-1 in fibronectin-induced mouse embryonic stem cell proliferation: role of FAK, RhoA, PI3K/Akt, and ERK 1/2 pathways. J Cell Physiol 226: 267-275, 2011.

60. Watson CS, Jeng YJ, Hu G, Wozniak A, Bulayeva N and Guptarak J: Estrogen- and xenoestrogen-induced ERK signaling in pituitary tumor cells involves estrogen receptor- $\alpha$ interactions with G protein- $\alpha i$ and caveolin I. Steroids 77: 424-432, 2012. 